\title{
Projeto de extensão: imigração e inclusão social no Oeste do Paraná, Brasil
}

\author{
Extension project: immigration and social inclusion to the West of Paraná, Brazil \\ Proyecto de extensión: inmigración y inclusión social en el Oeste de Paraná, Brasil
}

Recebido: 15/10/2021 | Revisado: 25/10/2021 | Aceito: 27/10/2021 | Publicado: 31/10/2021

Ethol Exime

ORCID: https://orcid.org/0000-0002-6962-8088 Universidade Estadual do Oeste do Paraná, Brasil

E-mail: eeetholl@hotmail.com

Cleoson Moura dos Reis

ORCID: https://orcid.org/0000-0002-8490-6357

Universidade Federal do Rio Grande do Sul, Brasil

E-mail: cleosonmoura@gmail.com

Aline Costa Gonzalez

ORCID: https://orcid.org/0000-0001-9672-8562

Universidade Estadual do Oeste do Paraná, Brasil

E-mail: alinecg_15@hotmail.com

Juscelino Martins Costa Junior

ORCID: https://orcid.org/0000-0001-6166-6461

Universidade Estadual do Oeste do Paraná, Brasil E-mail: juscelinojunio_@hotmail.com

Mariell Lima Costa

ORCID: https://orcid.org/0000-0002-4292-9673

Universidade Estadual do Oeste do Paraná, Brasil

E-mail: mariell_lima@hotmail.com

Alvori Ahlert

ORCID: https://orcid.org/0000-0001-9984-6409

Universidade Estadual do Oeste do Paraná, Brasil

E-mail: alvoriahlert@yahoo.com.br

Vinícius Mattia

ORCID: https://orcid.org/0000-0002-3533-9245

Universidade Estadual do Oeste do Paraná, Brasil E-mail: vinicius_mattia@hotmail.com

Wilson João Zonin

ORCID: https://orcid.org/0000-0002-3364-5599

Universidade Estadual do Oeste do Paraná, Brasil

E-mail: wzonin@yahoo.com.br

\begin{abstract}
Resumo
Os imigrantes que chegam no Brasil enfrentam muitos desafios e dificuldades. Entre eles estão o domínio do idioma e a assimilação cultural, que impactam diretamente no seu processo de inclusão social e na sua qualidade de vida. Sendo assim, foi elaborado um projeto, cujo objetivo era auxiliar os imigrantes no processo de acolhimento, que consistiu, principalmente, em aulas gratuitas de língua portuguesa e da cultura brasileira. Buscou-se responder como os projetos de extensão podem contribuir para a inclusão social dos imigrantes haitianos na região Oeste, do Estado do Paraná, Brasil? Este trabalho é de natureza qualitativa, cuja metodologia consiste em uma ideia simples de compartilhamento de conhecimentos, entre tutores e participantes, por meio de um questionário respondido por 27 participantes para obtenção dos dados. Concluiu-se que os projetos de extensão possuem fortes impactos na vida dos imigrantes haitianos, facilitando assim o processo de inclusão social através da aprendizagem linguística.
\end{abstract}

Palavras-chave: Inclusão social; Imigração; Ator rede; Acolhimento dos haitianos; Solidariedade.

\begin{abstract}
Immigrants arriving in Brazil face many challenges and difficulties. Between them are language proficiency and cultural assimilation, which directly impact their social inclusion process and their quality of life. Therefore, a project was elaborated, whose objective was to help immigrants in the welcoming process, which consisted mainly of free classes in Portuguese language and Brazilian culture. We sought to answer how extension projects can contribute to the social inclusion of Haitian immigrants in the western region of the state of Paraná, Brazil. This is a qualitative work, whose methodology consists of a simple idea of knowledge sharing, between tutors and participants, through a questionnaire answered by 27 participants to obtain the data. Concludes that the extension projects have powerful impacts on the lives of Haitian immigrants, thus assisting the process of social inclusion through linguistic learning.
\end{abstract}

Keywords: Social integration; Immigration; Rede actor; Reception of haitians; Solidarity. 


\begin{abstract}
Resumen
Los inmigrantes que llegan a Brasil se enfrentan a muchos retos y dificultades. Entre ellas, el dominio del idioma y la asimilación cultural, que impactan directamente en su proceso de inclusión social y calidad de vida. Por ello, se elaboró un proyecto cuyo objetivo era ayudar a los inmigrantes en el proceso de acogimiento, que consistía principalmente en clases gratuitas de lengua portuguesa y cultura brasileña. Buscamos responder a la pregunta de cómo los proyectos de extensión pueden contribuir a la inclusión social de los inmigrantes haitianos en la región oeste del estado de Paraná, Brasil. Este trabajo es de carácter cualitativo, cuya metodología consiste en una simple idea de intercambio de conocimientos, entre tutores y participantes, a través de un cuestionario contestado por 27 participantes para obtener los datos. Concluye que los proyectos de extensión tienen un fuerte impacto en la vida de los inmigrantes haitianos, facilitando así el proceso de inclusión social a través del aprendizaje lingüístico.

Palabras clave: Inclusión social; Inmigración; Red de actores; Acogimiento de haitianos; Solidaridad.
\end{abstract}

\title{
1. Introdução
}

Nos últimos anos o Brasil se transformou em um lugar de refúgio e acolhimento para imigrantes devido aos problemas de origem social, econômica, ambiental e política de países como o Haiti, Venezuela, Bolívia, Senegal, Colômbia, entre outros. "De um modo geral a migração é quase sempre um fenômeno forçado. A opção espontânea dá-se muito excepcionalmente. Como fenômeno forçado, é consequência de necessidades de sobrevivência" (Ahlert, 2021, p. 119). Especificamente no caso do Haiti, os problemas são quase sempre de crise política, bem como de constantes catástrofes ambientais, como os terremotos, que aumentam a migração dos haitianos. O país caribenho vive, além disso, turbulência de desigualdade social, um povo faminto na busca para suprir necessidades básicas, alimentares, e da pobreza (Exime, 2021), gerando uma grave crise imigratória.

Desde então, ficou comum ver os haitianos tentando sair do país para escapar da pobreza extrema. Se considerarmos somente o ano de 2018, por exemplo, registrou-se um quantitativo de 106,1 mil haitianos legais, além dos haitianos o Brasil recebeu um total de 774,2 mil imigrantes, esses cidadãos buscam essencialmente melhorias na qualidade de vida ou a preservação da própria vida, além disso, a possibilidade de ajudar a família que muitas vezes permanecem no seu país de origem, embora a vida almejada no novo país seja uma profunda incógnita (Simões, Cavalcanti \& Pereda, 2019; Cavalcanti, De Oliveira \& De Macedo, 2019). Nesse contexto, considera-se necessária a realização de ações para promover uma melhora nas condições de vida dessas pessoas, a partir de projetos de extensão e na perspectiva de inclusão social.

A inclusão social dos imigrantes no Brasil se depara com a falta de organizações governamentais para o recebimento dos imigrantes autorizados a entrar no Brasil de forma legal. As políticas públicas de acolhimento não existem para abordar um dos problemas específicos de boas-vindas, que é o processo de inclusão. Desta forma, no Brasil, percebe-se que existe um controle imigratório, relacionado a direito de entrada e saída e documentações permitidas para permanecer no território brasileiro, mas todas as outras mais questões como educação, cursos profissionalizantes, alojamentos, direcionamentos e capacitações permanecem por conta dos imigrantes e empresas que pretendem contratar os mesmos. (Diniz \& Neves, 2018; Bortoloto, 2020).

É essencial que haja um processo de acolhimento que promova a inclusão social, auxiliando-os a encontrarem uma forma de viver socialmente bem. Igualmente fundamental, é mostrar quais as responsabilidades adquiridas e o conhecimento das regras estabelecidas, a fim de manter um processo de adaptação e convivência na nova sociedade. Dessa forma, ações para formação, inserção no mercado de trabalho e criação de políticas públicas para essa população são imprescindíveis, e com apoio da sociedade civil, devem estar entre as prioridades para o Poder Público. Nesta perspectiva, o fator trabalho é importante, observando o número geral de pessoas que permaneceram no país até 2018 (492,7 mil), sendo que o total de carteiras de trabalho emitidas foi de 305.796 entre 2010 e 2018 (Simões, Cavalcanti \& Pereda, 2019).

Segundo o Instituto Brasileiro de Geografia e Estatística (IBGE, 2020a), a situação do Brasil não é muito favorável no âmbito de empregabilidade, pelo fato de que a taxa de desemprego figura entre $10 \%$ e 13,7\% em 2020, porém, o que mais 
chama atenção é a média salarial dos imigrantes ( $\mathrm{R} \$ 1.500,00)$, se comparada a dos brasileiros ( $\mathrm{R} \$ 2.500,00)$. É uma diferença muito considerável, que impacta diretamente na qualidade de vida de quem escolhe o Brasil como segunda casa. Isso se percebe na citação abaixo e, com maior impacto com a pandemia da covid-191,

A maior parte dessa população (o refugiado e todos aqueles que partilham sua residência contribuindo ou não para a renda do domicílio) vive em domicílios com no máximo dois quartos para dormir. De forma geral, embora tenha seus gastos comprometidos com aluguel e outras despesas ligadas à moradia (água, luz, etc.), sua renda não atende às necessidades do domicílio, o que explica redução de alimentação, empréstimos diversos, gastos reduzidos (menos do que $\mathrm{R} \$ 100,00 /$ mês) com educação, saúde e lazer, resultando na impossibilidade de investimento em qualidade de vida e progresso individual. A população refugiada analisada encontra-se, de maneira geral, alijada do sistema de crédito nacional e endividada (De Mello, 2019, p. 27).

Os imigrantes que estão nesta situação, com dívidas e ainda com um emprego que não permite a possibilidade de viver bem, vê a chegada da covid-19 no Brasil como mais um desafio a ser enfrentado. Na contabilidade de inúmeras empresas afetadas pela pandemia, das 4,0 milhões de empresas envolvidas em uma pesquisa do IBGE, 70\% tiveram impactos negativos, o que envolve diretamente na demissão de funcionários, e isso não é diferente para os imigrantes (IBGE, 2020b).

Para reduzir os impactos negativos da pandemia na vida das pessoas com baixa ou nenhuma renda, o governo criou o auxílio emergencial ${ }^{1}$. Porém, de modo geral, seguindo as regras para obter esse benefício, os refugiados apresentaram dificuldade para aquisição do mesmo. Algumas entidades, como a Agência da ONU para refugiados (ACNUR) e a Organização Internacional para as Migrações (OIM) chegaram a fazer um "passo a passo" em diversos idiomas para facilitar, com vários pontos de referência para estabelecer contatos caso houvessem dúvidas (IMDH, 2020).

No Brasil, no âmbito da educação, os problemas de inclusão social, falta de acesso a escolas, universidades, de cursos profissionalizantes, além de poucas verbas, que já existiam, o agravamento com a pandemia impactou diretamente os Programas direcionados aos imigrantes, prejudicando o progresso do estrangeiro para inserção na sociedade e, principalmente, na qualificação para imersão no mercado de trabalho. Outro fator importante sobre a educação está relacionado às metodologias utilizadas nas escolas, que não se adaptam às novas demandas e novos princípios para o desenvolvimento inclusivo mediante as tecnologias de comunicação. Todos sabemos que garantir o bem-estar e o direito fundamental básico das pessoas e o acesso à educação, sendo elas brancas, negras, imigrantes ou qualquer que seja sua origem, é dever do Estado. Buscar uma metodologia educacional para os mais necessitados, junto à valorização dos professores, que muitas vezes precisam se reinventar para ajudar na construção do novo (Ahlert, 2001), visando à redução da pobreza na sociedade.

Nesta perspectiva, esse trabalho objetiva promover uma reflexão sobre as ações de solidariedade e a atuação de diferentes atores sociais na criação de grupos que visam a inserção social de imigrantes no Brasil, além de incentivar debates nas universidades públicas sobre o tema. Com a sua aplicação, espera-se elucidar a seguinte questão: Como os projetos de extensão podem contribuir para a inclusão social dos imigrantes haitianos na região Oeste do Estado do Paraná, Brasil?

\section{Referencial Teórico}

Esta seção objetiva apresentar de forma breve a construção teórica que sustentaram ou contribuíram para o desenvolvimento do trabalho bem como refletem o papel de revelar especificidades em construções não convencionais. Neste sentido, aproximam-se elementos da ideia de Tecnologia Social (TS) e da Teoria Ator-Rede.

\footnotetext{
1 O Auxílio Emergencial é um benefício financeiro destinado aos trabalhadores informais, microempreendedores individuais (MEI), autônomos e desempregados, e tem por objetivo fornecer proteção emergencial no período de enfrentamento à crise causada pela pandemia do Corona vírus - COVID 19.
} 


\subsection{Tecnologia social (TS)}

Um dos aspectos essenciais da Tecnologia Social (TS), se refere ao seu papel na dinamização e ampliação de processos democráticos. De acordo com Fonseca e Serafim (2010), o seu fundamento encontra-se articulado na geração de coletividade e a participação dos atores, objetivando simultaneamente, de forma concisa e estratégica, a constituição de uma nova perspectiva de desenvolvimento mais inclusiva e participativa.

O sentido de TS é proveniente de um processo com peculiaridades a seus termos congêneres, de Tecnologia Intermediária e Tecnologia Apropriada. Propõe por um lado, uma visão de sociedade, e por outro, questiona a tecnologia convencional e o estilo de vida que a engendra. Devido ao seu interesse em questões sociais e políticas, associados ao processo de construção (social) da ciência e da tecnologia, o conceito de TS pode ser compreendido como o reflexo da ação coletiva de atores, diante de um ambiente socioeconômico e de laços sociais (associativismo) que representam, na sociedade, "um controle (auto gestionário) e uma cooperação (de tipo voluntário e participativo), e permite uma modificação no produto gerado passível de ser apropriada, segundo a decisão do coletivo" (Dagnino, 2014, p. 158).

Neste sentido, o projeto proposto neste trabalho segue essa vertente da TS, produzindo conhecimento de forma coletiva e inclusiva. Aspecto que demanda o envolvimento ativo de diversos agentes, dentre eles, o Estado, a comunidade científica e os movimentos sociais. Por outro lado, para alcançar níveis mais elevados em democracia, é preciso que os atores estejam devidamente engajados, seja na construção da tecnologia ou de políticas afins (Fonseca \& Serafim, 2010).

\subsection{A teoria ator rede}

A Teoria do Ator Rede, estruturada principalmente por autores como, Law (1994), Latour (2007), e Callon (1999), embora suas análises estejam mais ajustadas à ciência e à tecnologia, têm sido apontadas como morfologia do social. Apesar de não haver consenso sobre esta última referência, segundo "o princípio metodológico da simetria, todos os elementos que constituem uma cadeia de associações precisam ser explicados, sem nenhuma distinção prévia entre o social e o natural, o micro e o macro, as causas e os efeitos" (Schmitt, 2011, p. 93), considerando-se que as tentativas de arranjos são atributos da atividade performativa e recursiva da noção de redes.

A POA - Perspectiva Orientada ao Ator desenvolve um portfólio de conceitos, que substanciam a compreensão da atuação dos atores nas dinâmicas sociais. Dentre eles, o de agência humana como conceito central, que representa as capacidades de saber e de atuar dos atores, e se apresenta tanto na formação de rede de atores e suas relações sociais, quanto na canalização de elementos diversos “[...] (como demandas, bens, instrumentos, informações), através de pontos nodais de interpretação e interação" (Long, 2007, p. 50). Nas organizações sociais, a relevância em identificar "as concepções diferenciadas de poder, influência, conhecimento e eficácia podem modelar as respostas e estratégias dos diferentes atores" (Long \& Ploeg, 2011, p. 27).

Dessa forma, observar qual a funcionalidade da Teoria do Ator Rede, torna-se extremamente relevante, uma vez que, assim como a ideia desse projeto, trabalhos articulados em forma de rede, são ferramentas que auxiliam na "flexibilidade, horizontalidade, cultura democrática, entre outros". A abordagem de interdependência entre os atores e suas redes, mobilizam as relações e seus significados, propiciando a interconexão entre mundos díspares, excedendo os limites institucionais específicos, interligando uma grande diversidade social (Schmitt, 2011: 90, 92).

$\mathrm{Na}$ perspectiva da política, um dos aspectos mais importantes numa sociedade, principalmente na dos imigrantes haitianos em particular, deve-se levar à risca o processo da democratização a partir da inclusão, um ato que deve incluir qualquer pessoa, considera-se todos os atores como tendo um papel fundamental para incentivar a transparência através da cooperação, com intuito de oferecer real ajuda solidária sem retorno e ganhos financeiros. 


\section{Metodologia}

A pesquisa teve como objeto de investigação o Projeto de Extensão intitulado: "Acolhimento de imigrantes, diálogo de saberes para inclusão social solidária". Este projeto foi desenvolvido a partir do município de Marechal Cândido Rondon, região Oeste do estado do Paraná, com as seguintes coordenadas: $24^{\circ} 33^{\prime} 24^{\prime \prime}$ de latitude sul e 54 $33^{\circ} 24^{\prime \prime}$ longitude oeste, a uma distância de aproximadamente $580 \mathrm{~km}$ da capital do estado (Cidades Brasil, 2021), e uma população de aproximadamente 54.031 habitantes, conforme estimativas do IBGE (2021). Cidade que se encontra a Universidade Estadual do Oeste do Paraná - UNIOESTE, que possui o programa de Pós-graduação em Desenvolvimento Rural Sustentável, dirigido pelo coordenador Professor Wilson João Zonin² e que também coordena o projeto de extensão em questão que está vinculado a instituição.

Figura 1 - Mapa de localização do Oeste do Paraná com indicação para o município de Marechal Cândido Rondon.

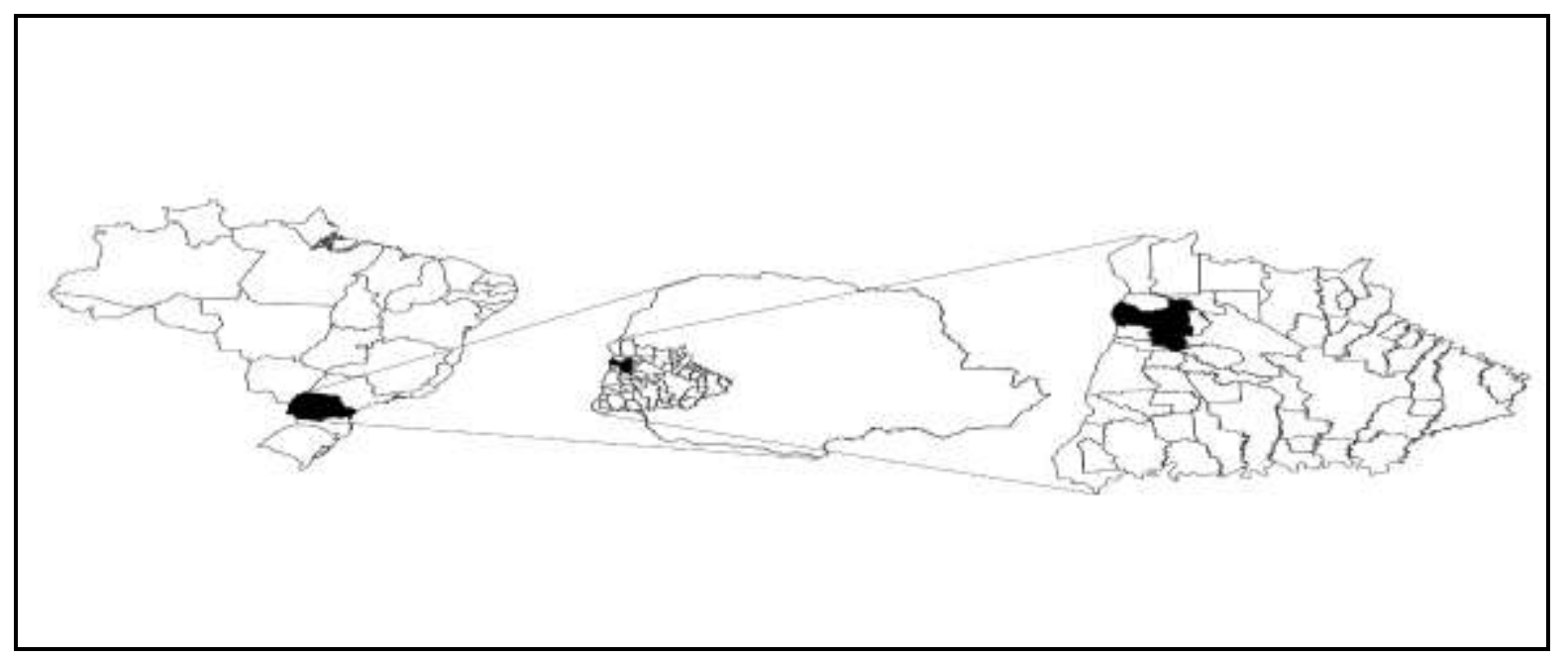

Fonte: Autores (2021).

A pesquisa que envolve o trabalho tem natureza qualitativa, "apresenta certas características particulares, sobretudo, na elaboração das deduções específicas sobre um acontecimento" (Bardin, 1977, p. 151). A coleta de dados foi realizada a partir de um questionário semiestruturado (Gil, 2009), composto por 12 questões abertas e fechadas aplicadas a 27 participantes. Desta forma, este trabalho envolve duas características importantes para uma discussão qualitativa na perspectiva de extensão: a primeira é a experiência vivida entre os tutores e os participantes ${ }^{3}$, ampliando assim o contato direto, e a segunda se deve a oportunidade de observar cada participante de forma única para aumentar a compressão e a elaboração deste projeto (Ludke \& Andre, 2013). Para analisar os dados obtidos através do questionário, empregou-se a análise de conteúdo junto à metodologia própria do projeto de extensão, que consiste em uma ideia simples de compartilhamento de conhecimento, pela qual no primeiro encontro, o "tutor" faz algumas perguntas simples aos participantes, a fim de compreender quais são suas necessidades, e a seguir dá sequência à programação do projeto, que será apresentado no tópico 4.3.

Neste sentido, com intuito de alcançar os objetivos da pesquisa, realizou-se a caracterização do projeto e a sistematização de dados das informações coletadas, a partir do questionário de pesquisa.

\footnotetext{
${ }^{2}$ Link para acessar o Currículos Lattes professor: http://lattes.cnpq.br/2139762598911476

${ }^{3}$ Cabe-se destacar que os participantes são alunos e os tutores são os professores (Acadêmico de pós-graduação).
} 


\section{Caracterização do Projeto de Extensão: uma Tecnologia Social em Rede}

Nesta seção apresentamos a Tecnologia Social Utilizada, instrumento de pesquisa e Programação do projeto de extensão. Desta forma, esse tópico tem a finalidade de ambientar o leitor sobre as condições em que o estudo foi realizado e a construção do projeto, servindo assim de exemplo para outras instituições.

\subsection{Tecnologia social utilizada}

As aulas desta tecnologia social foram ministradas a partir da necessidade de cada um, com perguntas pré-elaboradas. No entanto, os tutores tiveram a liberdade de levantar outros questionamentos, a fim de detectar a melhor forma de ajudá-los. Os encontros ocorreram de maneira individual ou em grupos de até 10 pessoas, sendo online ou presencial, de acordo com as condições que a pandemia permitiu. O intuito do projeto foi contribuir socialmente e construir diálogo de saberes, para o desenvolvimento social da comunidade de imigrantes. Esperou-se contribuir também para incentivar os imigrantes a aprender o português, a compartilhar suas culturas alimentares e de certa forma instigar o debate sobre imigrantes nas universidades, entre outros.

\subsection{Responsabilidade dos membros}

Foi de responsabilidade da coordenação geral do projeto desenvolver reuniões online preparatórias de planejamento com os participantes (ministrantes e alunos), ficando à cargo de discutir os assuntos com participantes que estiveram com dúvidas durante o projeto, condução das discussões de planejamento, anotação e organização das tomadas de decisões, estabelecendo assim um roteiro de realização do evento quando necessário. Além disso, serviu de referência para as decisões e elucidação de dúvidas dos demais organizadores e no decorrer do evento, realizou-se apresentações, com indicação e convite para tutores bem como, a necessidade de ter disponibilidade para resolução de eventuais problemas.

Aos demais colaboradores do projeto, coube o auxílio no planejamento prévio, a participação nas reuniões preparatórias online, o convite e confirmação de todos os padrinhos no geral, a confecção de material para divulgação e sua realização, a organização e o preparo das plataformas virtuais para realização dos debates que aconteceram, além do, ensino aos padrinhos sobre o acesso à plataforma, cadastramento no sistema de eventos da UNIOESTE, o monitoramento das inscrições e das participações, a elaboração de questionários de avaliação e de sistema de presença, a confecção de certificados para a comissão organizadora e participantes, elucidação de dúvidas e resolução de problemas em geral.

Lembrando que todo o plano de trabalho foi realizado de maneira online ou presencial, respeitando as normas sanitárias exigidas para a não propagação da covid -19, e remota, através de TICs disponíveis e que tiveram efetividade no acesso às demais pessoas. Desde o início da covid -19 , as tecnologias em particular os aplicativos de chamadas, acabaram se transformando em ferramentas importantes e úteis para disponibilizar e facilitar o acesso à educação, e este projeto aproveitou bem esta oportunidade para suprir a necessidade dos imigrantes através de aprendizagens linguísticas (Silva \& Lima, 2021).

\subsection{Programação do projeto de extensão}

Criou-se esta programação (Quadro 1) para ajudar os participantes e tutores nas questões dos planejamentos pessoais e profissionais, com objetivo de cooperarem de uma forma mais contundente no projeto de extensão. 
Quadro 1 - Programação do projeto de extensão.

\begin{tabular}{|l|l|}
\hline \multicolumn{1}{|c|}{ TEMA } & MINISTRANTES/PARTICIPANTRES \\
\hline Data prevista para o início: 20 de setembro de 2020 e & Pessoas que decidiram ajudar, e inscreveram-se quando o \\
término: 20 de dezembro de 2020. Os encontros ou & projeto foi divulgado e começou sua programação, da \\
aulas foram preferencialmente aos Domingos na parte & mesma maneira que os demais participantes. \\
da tarde ou outros dias e horários combinados. & \\
Variou-se de 1 a 7 encontros por semana. Abertura & \\
geral: de 20/09 a 20/10, encontros sobre o Idioma & \\
português: de 20/10 a 20/11, encontros & \\
preferencialmente sobre cultura brasileira: de 20/11 a & \\
13/12, Palestras e aulas de português: Dia 20/12. & \\
Encerramento & \\
\hline
\end{tabular}

Fonte: Autores (2021).

\section{Resultados e Discussão}

Inicia-se esta seção a partir dos dados explicativos com os resultados obtidos durante o projeto, além de como funcionou durante esse tempo, e por fim apresentamos os dados do questionário.

\subsection{Resultados}

A primeira parte dos resultados já obtidos se estrutura a partir das aulas que ocorreram aos domingos, entre as 14:00 e 16:00 horas. Além de auxiliar os alunos participantes a encontrarem cursos técnicos e profissionalizantes, o projeto apoiou os imigrantes de nacionalidade haitiana a conseguirem empregos por meio de contato com entrevistadores. Os imigrantes foram auxiliados a se prepararem visual e emocionalmente e com linguagem adequada a fim de causar um impacto positivo durante as entrevistas.

A segunda parte dos resultados consistiu na divulgação das culturas alimentares dos países por meio da internet, pela qual se planejou fazer uma live 4 por mês para divulgar os pratos típicos dos países. Sendo que, a primeira foi realizada no dia 17 de outubro de 2020, cujas comidas típicas da Venezuela e do Haiti foram apresentadas. A live até o momento foi vista por 132 pessoas com engajamento e interação.

Os participantes, imigrantes do Haiti, tiveram uma excelente participação. Foi notório o progresso linguístico de cada um dos 27 participantes, resultados demonstrados nos próximos parágrafos. Através deste projeto de extensão, os haitianos conseguiram obter vários benefícios, como ajuda de cestas básicas e preparações para entrevistas de emprego, cujo agora, vários dos participantes se encontram trabalhando.

Como é possível constatar, uma parte dos objetivos já foram alcançados, e o engajamento de todos os atores é surpreendente, no intuito de cumprir os objetivos e ir além do estabelecido. Por meio deste projeto foi possível ampliar a capacidade de ajudar os imigrantes nos aspectos educacionais, incentivar novos debates para formulação de políticas públicas, profissionais e, de fato, impulsionar a inclusão social.

\subsection{Resultados antes e depois do projeto de extensão}

Nesta etapa encontram-se dados dos participantes no projeto de extensão que preencheram os questionários, pelo qual se obteve 27 respostas. Destas, pode-se contatar que 11 imigrantes possuem ensino superior, 15 deles possuem nível tecnólogo ou profissionalizante, e apenas um imigrante realiza atividade de auxiliar de produção, que não possui nenhuma qualificação. Nos resultados do Quadro 2, percebemos que existe uma imigração de alta qualificação.

\footnotetext{
${ }^{4}$ Link da live: https://youtu.be/_fzMLd1GAio
}

${ }^{5}$ Refere-se até a data de 04 de outubro de 2021. 
Quadro 2 - Profissões e níveis educacionais.

\begin{tabular}{|l|c|c|c|}
\hline N/P & NíVEL 1 & NÍVEL 2 & NÍVEL 3 \\
\hline & 2 Engenheiros em informática & $\begin{array}{c}\text { Técnico em instalação e manutenção de } \\
\text { ar condicionando }\end{array}$ & Auxiliar de produção \\
\hline & Enfermeira & 4 pedreiros profissionais & \\
\hline & Jornalista & Mecânico & \\
\hline & Professor de informática & Fotógrafo profissional & \\
\hline & Jornalista cultural & 2 Comerciantes & \\
\hline & Professor universitário & 2 Eletricistas & \\
\hline & Téc. Agronomia & Técnico em mecânica, pintor & \\
\hline & Professora de criança & Vendedor / comercial & \\
\hline & Téc. Mecânico & Profissional da construção civil (mestre) & \\
\hline
\end{tabular}

Fonte: Autores (2021).

Nesta perspectiva, a tendência de encontrar imigrantes haitianos no mercado de trabalho em um emprego que exige certo grau de instrução seria grande, porém não é o que vemos na realidade. O número de imigrante existentes no Brasil, que buscam uma vida digna com emprego que possa contribuir para obterem uma qualidade de vida melhor do que foi deixado para trás no seu país de origem, é significante, por isso, quando se pensa nos imigrantes, devemos ter consciência do seu impacto econômico e social na sociedade que se inserem. Os cidadãos haitianos que representavam o maior número de imigrantes no Brasil até 2018, precisam de apoio governamental e não-governamental, como quaisquer outros imigrantes, para alcançarem seus objetivos relacionados à inclusão (Simões, Cavalcanti \& Pereda, 2019; Cavalcanti, De Oliveira \& De Macedo, 2019).

Assim, quando se trata do quesito trabalho, os imigrantes que fazem parte desta análise, são bem qualificados para o mercado de trabalho brasileiro, sendo que a maioria possui profissões e excelentes qualificações (Quadro 2), já que, quando falamos de trabalho, é necessário levar em conta a educação. Segundo Ahlert (2001), a educação é fundamental em qualquer sociedade ou lugar do mundo, ela nos ajuda a criar o novo, ou seja, fazer diferença através dos estudos, incluir os mais necessitados como é no caso dos imigrantes haitianos no Oeste do Paraná.

Nesta perspectiva educacional, no caso dos imigrantes, trata-se de uma educação linguística, sendo que, antes do projeto de extensão, a maioria dos imigrantes não falavam e nem compreendiam o idioma português. Podemos visualizar seus níveis linguísticos no Gráfico 1, a seguir. 
Gráfico 1 - Nível de português falado pelos imigrantes antes do projeto de extensão.

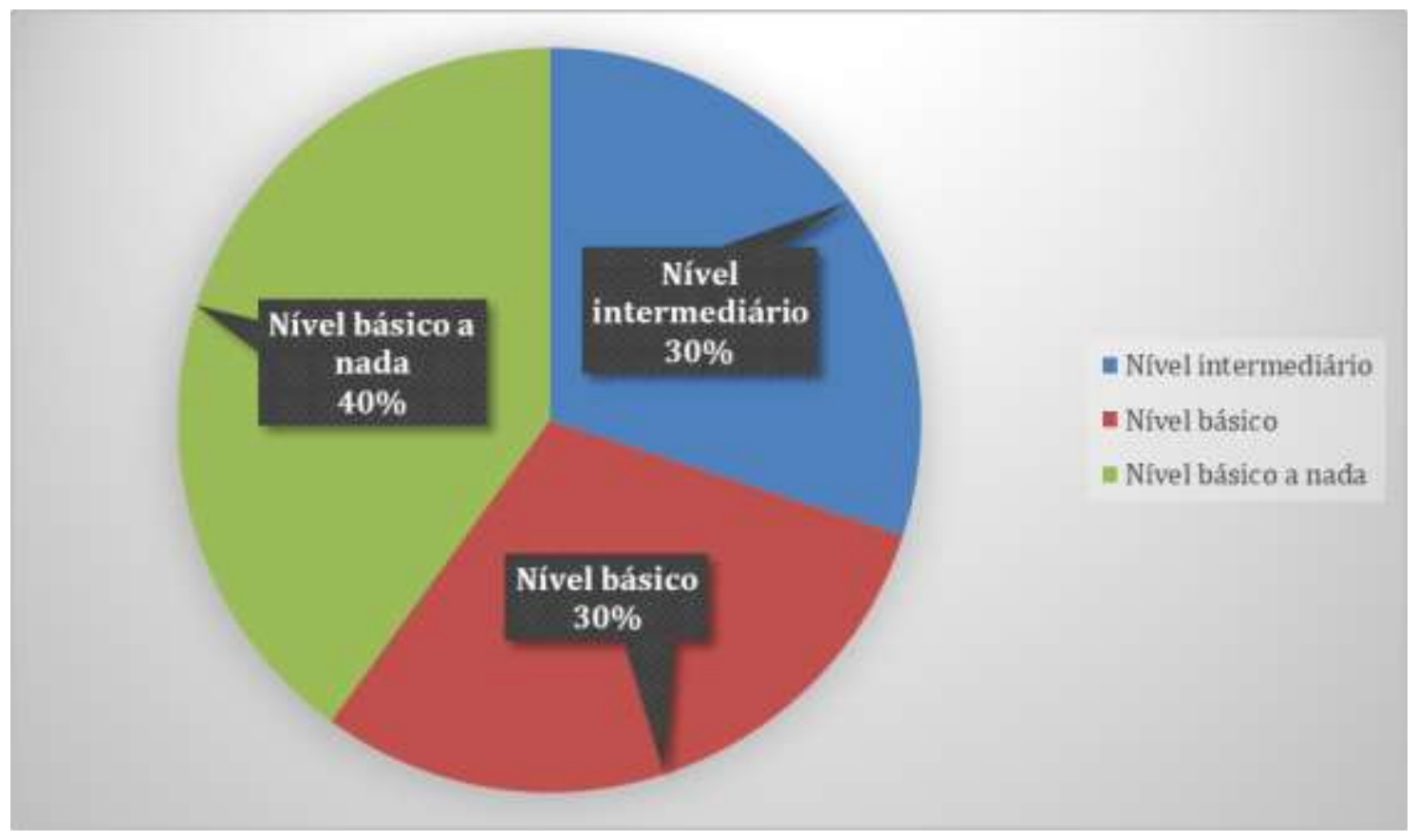

Fonte: Autores (2021).

Os resultados evidenciaram que $30 \%$ foram atribuídos ao nível intermediário, $40 \%$ ao nível básico e outros $30 \%$ que não falavam nada do idioma português e, que frequentemente se comunicavam em crioulo e francês (os dois idiomas oficiais do Haiti). Mesmo tendo a opção de assinalarem o nível avançado, a pesquisa constatou que esta representa $0 \%$ dos resultados. Compreende-se que esta barreira linguística pode ser um dos motivos que impedem uma inclusão mais significativa dos imigrantes na sociedade brasileira. Além disso, é claramente uma questão de falta de políticas públicas alinhadas ao acolhimento do imigrante (Diniz \& Neves, 2018).

Neste contexto, são necessários outros tipos de olhares sobre esta situação, já que o problema existente não pode ser pensado apenas para o caso dos imigrantes e, sim, para quaisquer outros grupos, na perspectiva de inclusão social, educacional ou linguística. Contudo, de ponto de vista crítico, esta situação se deve a como são tratados os problemas da educação ligado a linguística no Brasil, associado ao fato da pouca importância, da mínima valorização que se dá à aprendizagem de idiomas, lembrando também dos poucos ou quase nada de incentivos para os professores que trabalham com as disciplinas da linguística (Diniz \& Neves, 2018).

Desta forma, o projeto de extensão ocupa um papel fundamental de suma importância para os imigrantes, em razão de falta de políticas públicas alinhadas a seu interesse de aprendizagem linguística, seus poucos conhecimentos do idioma português. Isso pode impactar no acesso aos empregos, melhores salários, o que se torna parte dos motivos para não conseguirem um emprego com suas qualificações que trazem de seus países de origem. Porém, a situação teve mudanças significativas no final do projeto de extensão (Gráfico 2). 
Gráfico 2 - Nível de português falado pelos imigrantes depois do projeto de extensão.

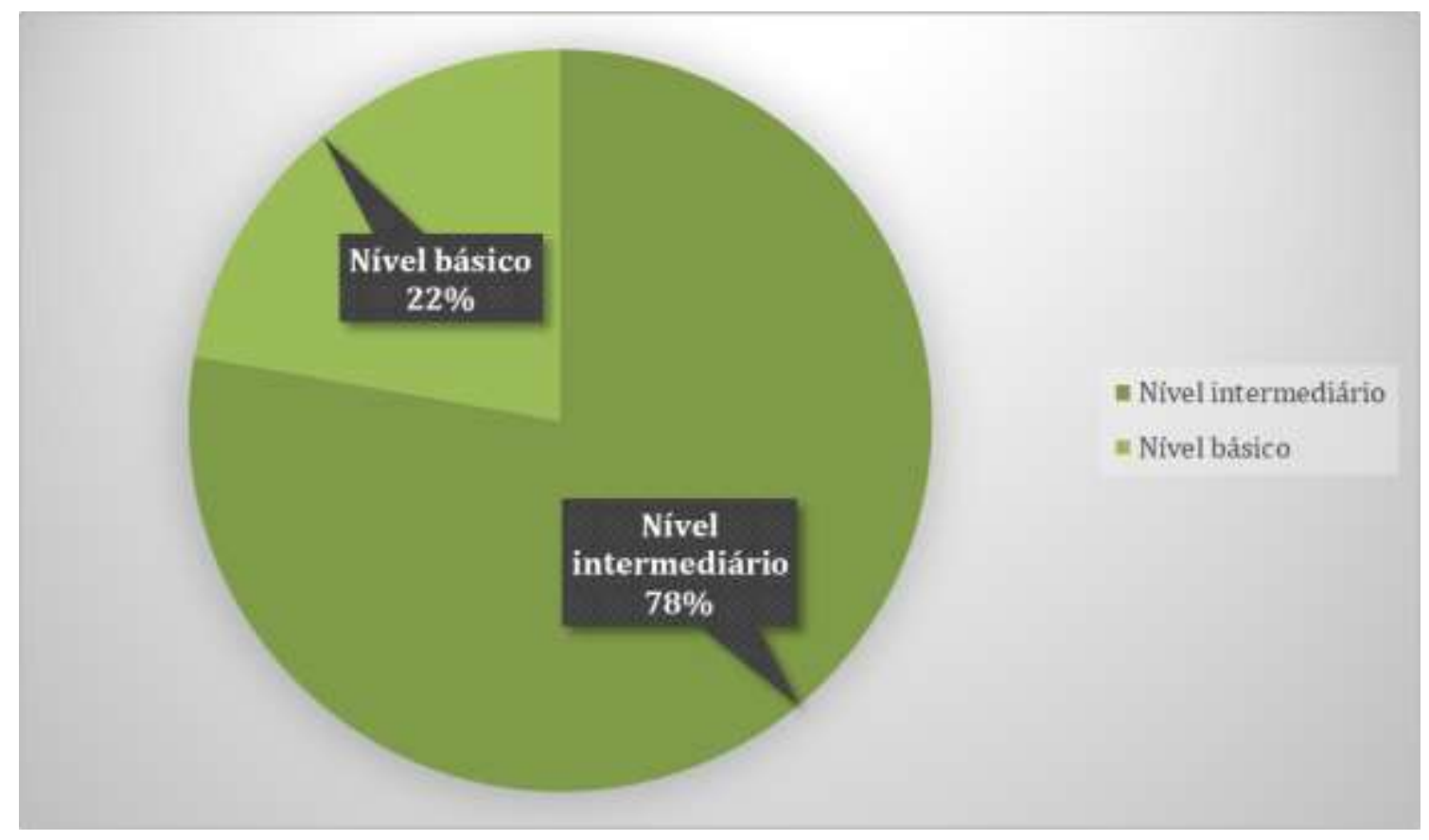

Fonte: Autores (2021).

No contexto da educação, relacionado ao idioma de português, $78 \%$ passaram a se expressar melhor no final do projeto, tornando-o um número importante numa construção conjunta que deu certo por meio da solidariedade. Dos $40 \%$ que quase não falavam nada, agora temos $22 \%$ que passaram para o nível básico. Esse progresso é um passo importante para a inclusão dos imigrantes haitianos, além de impacto direto sobre sua qualidade de vida, e na ideia de contribuir com a sociedade onde vivem, economicamente e socialmente.

A aprendizagem do idioma para os imigrantes tem impacto no desenvolvimento local, das comunidades e das cidades que vivem, por contribuírem também através de impostos, mão de obra para as empresas, apenas para citar alguns exemplos de contribuição. Atrelado a isso, o desenvolvimento pode ser distinto em diferentes lugares e região, quando se reflete o que é desenvolvimento, neste contexto, refere-se aqui desenvolvimento no aspecto social de bem-estar como cidadãos que busquem progredir, alcançar um futuro melhor e ajudar suas famílias a evoluírem (Pike, Rodríguez-Pose \& Tomaney, 2007).

Ainda neste aspecto da evolução, os imigrantes que fizeram parte do projeto de extensão, tiveram progresso importante para pensar de fato na inclusão social, evitando de forma inteligente a desigualdade, por isso apresentamos a seguir alguns exemplos dos seus progressos através de cartas e trabalhos realizados ao final das etapas do curso de extensão.

\subsection{Progresso dos participantes}

O progresso dos participantes está relacionado com as práticas diárias dos estudantes, as participações dos tutores por meio dos aplicativos como whatsapp e google meet, que ajudam a fortalecer os laços para que cada um possa estudar os conteúdos, receber ajuda de correções gramaticais fora dos horários combinados, entre outras. Essas atitudes e atividades foram fundamentais para a evolução de cada participante. Assim, ressalta-se que os tutores não obedeceram às horas mencionadas no projeto, justamente pelas necessidades dos participantes.

Nesta perspectiva, a prática ajuda a fazer o acúmulo de informações que permite um avanço no quesito de aprendizagem de forma mais rápida. Uma forma que potencializam conhecimento dos alunos mesmo quando apresentam alto grau de dificuldade no ensino-aprendizagem (Silva, Corrêa, Charão \& Lima, 2017). Neste trabalho de inclusão social linguística (Figura 2), não foi diferente, justamente pelo avanço dos participantes. 
Research, Society and Development, v. 10, n. 14, e212101421816, 2021

(CC BY 4.0) | ISSN 2525-3409 | DOI: http://dx.doi.org/10.33448/rsd-v10i14.21816

Figura 2 - Exemplo de progresso no idioma português mediante tarefas.

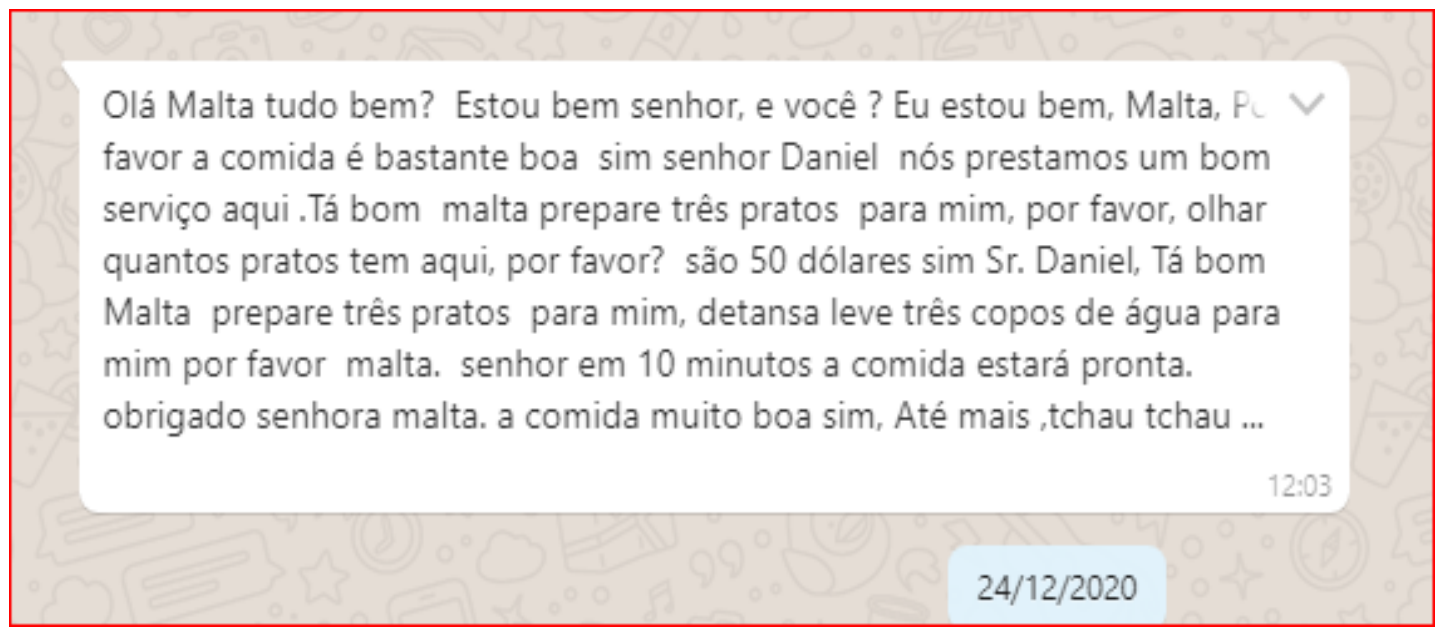

Fonte: Autores (2021).

Nesta atividade ficou claro o esforço de um participante, que se dedicou durante o projeto para apreender o português do dia a dia, estabelecendo uma conversa com uma outra pessoa de forma ilustrativa, o que nos permite avaliar a importância e o que significa este projeto de extensão na prática para os imigrantes.

A seguir (Figura 3) ilustramos outro caso de sucesso.

Figura 3 - Exemplo de progresso no idioma português mediante tarefas.

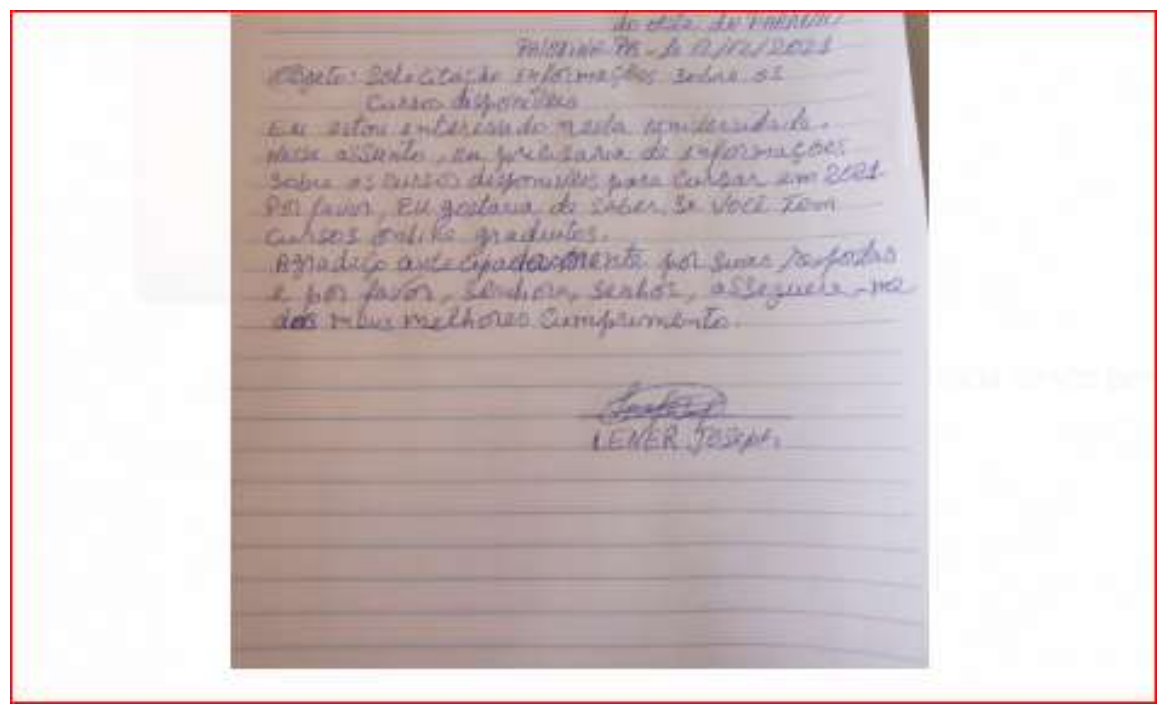

Fonte: Autores (2021).

Nesta ocasião o participante aproveitou para averiguar informações sobre os cursos de graduação numa universidade, intenção expressa em sua carta que, além do progresso linguístico, permite constatar um português compreensível, que pode ser lido por qualquer pessoa que entenda o idioma. Nota-se a motivação que fez o imigrante apreender a língua, participar no curso, com o objetivo de continuar seus estudos.

Na sequência vemos outro exemplo dessa evolução linguística dos imigrantes a partir do projeto de extensão. 
Figura 4 - Exemplo de progresso no idioma português mediante tarefas.

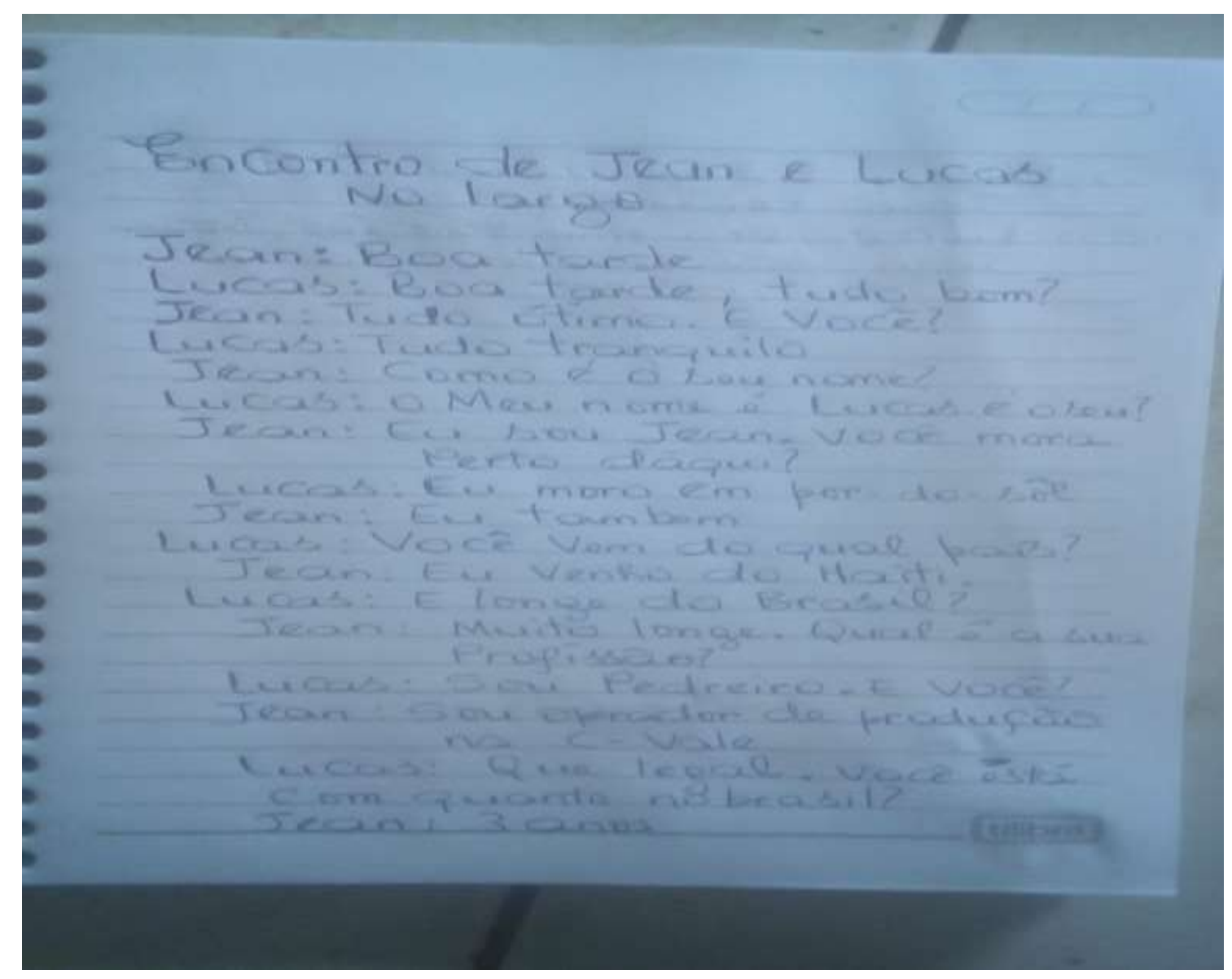

Fonte: Autores (2021).

Aqui se percebe o quanto a educação vai além de um direito do cidadão. Ela é a melhor possibilidade para um sujeito sair da pobreza, se defender em seus direitos políticos, sociais, além de contribuir para diminuição da desigualdade. Neste projeto de extensão destaca-se também os tutores, professores que fizeram parte desta belíssima contribuição intelectual, o que se evidencia na evolução do participante constatado na Figura acima. Uma contribuição solidária sem segunda intenção, uma cooperação de ensino que permitiu um avanço intelectual.

Do ponto de vista de cooperação, a intervenção por meio do projeto de extensão passou a ser uma alternativa que merece o esforço em comum para uma causa justa e inclusiva. Cooperar em favor dos mais fracos para melhor distribuição evolutiva de uma sociedade é um caminho fundamental nestes tempos tão marcados pela migração forçada de contingentes humanos. Neste aspecto, o projeto de extensão em estudo se destaca como uma nova forma de cooperar com relação aos programas tradicionais, por exemplo, entre nações, empresas, sendo as mais comuns. Portanto neste caso, é uma cooperação entre pessoas preocupadas com o bem-estar de cidadãos que precisam de ajuda intelectual, no caso, apreender um novo idioma para melhorar suas vidas, além de visar o processo de inclusão social (Exime, 2021; Vestena, Beckmann \& Peixoto, 2020).

Contudo, vale ressaltar que durante o projeto vimos em cada um dos participantes a evolução e o crescimento na formação acadêmica através da metodologia usada, que teve a participação dos 27 haitianos, e que permitiu ver como a acolhida e a integração de imigrantes tem lacunas e falhas no Brasil. Este é um fato relevante, já que a educação é muito desigual, a inclusão na América Latina e no Brasil tem sido debate para enfrentar ideias que são contra a ciência. Nesta realidade, as questões sociais perdem valor perante os governantes, e os fracassos registrados das políticas públicas nesta perspectiva são uma situação que afeta a sociedade democrática de bem-estar para todos. 


\section{Considerações Finais}

Conclui-se que o projeto auxiliou os alunos participantes a encontrarem cursos técnicos e profissionalizantes. É um projeto que apoia os imigrantes de nacionalidade haitiana para conseguirem empregos por meio de contato com entrevistadores, além de receberem auxílio na preparação para as entrevistas de entrevistas de emprego, a fim de causar um impacto positivo durante o processo seletivo.

Constatou-se que os imigrantes em questão possuem alto grau de educação, desde ensino superior ao profissionalizante, uma confirmação contrária ao que se apresenta no relatório de 2019 do portal Observatório das Migrações Internacionais (OBMigra), que afirma que a maior parte dos imigrantes haitianos possui um grau de instrução abaixo de ensino médio e que nem completaram seu ensino fundamental.

Sendo assim, por meio deste projeto, ficou claro que o problema de inclusão social dos imigrantes é uma necessidade que não pode e não deve ser ignorada pelas instituições, organizações e pelos governos nos âmbitos locais e federal. No caso do Brasil, acreditamos que a falta de políticas públicas não pode ser relacionada com investimentos ou falta de verbas para elaboração de uma política alinhada a ajudar os imigrantes, mas, muito mais por uma questão de vontade política, de governo que promete, sem ideias claras de como cumprir com as promessas, dizendo que os imigrantes são bem-vindos, porém, sem condição de uma vida digna. Assim, cabe destacar que a inclusão pode trazer benefícios para a sociedade, impulsionar ainda mais o desenvolvimento local e comunitário. Contudo, vale lembrar que projeto de extensão no Brasil é uma atividade recorrente.

Desta forma, pode-se afirmar que um projeto como este pode servir de exemplo multiplicador para outras comunidades, em universidades em todo o território brasileiro. Também pode ser indicado como projeto de inclusão social do imigrante, levando em conta as necessidades dos imigrantes, porque é um fator importante para o sucesso dos mesmos. O projeto ainda nos alerta sobre como pode ser realizado um projeto de extensão alinhado aos imigrantes, levando em conta as suas necessidades no momento, e não apresentar um curso de forma genérica para todos, servindo assim, para evitar qualquer tipo de desistência por parte dos participantes no curso.

Por fim, o estudo nos encoraja a recomendar às empresas da região para que contratem os imigrantes e invistam na educação linguística dos mesmos, que efetuem esforços para contribuir com eles em sua adaptação à cidade, Estado e país, que criem mecanismos para melhor aproveitar as qualidades e qualificações dos imigrantes, sendo isso um fator importante para ajudar a melhorar a qualidade de vida deles, na perspectiva de ganhar mais espaço para crescer pessoalmente e profissionalmente. Isto poderá se traduzir em ganhos para as empresas, alinhar seus interesses às inteligências dos contratantes. Por outro lado, permanece a crítica a ser atribuída aos imigrantes haitianos que não se esforçaram em aprender o idioma português por conta própria, autolimitando-se em seu progresso econômico e social.

Indica-se ainda a importância de pesquisas futuras para discutir o tema de forma geral, e desenvolver pesquisas que investiguem o processo de inclusão social, considerando outras comunidades de imigrantes, além dos haitianos. Sugere-se também pesquisas que tratem da importância dos imigrantes nas sociedades do mundo e seus impactos nas economias locais, em particular a brasileira. E por fim, indica-se pesquisas que incentivem a criação de políticas públicas para facilitar o acesso aos direitos à educação de qualidade para os imigrantes em universidades públicas, consonante com seus princípios e valores culturais.

\section{Agradecimentos}

Primeiramente agradecemos à comunidade dos haitianos, por permitirem o acesso às informações através dos questionários preenchidos para a realização deste trabalho; aos tutores que dicaram seu precioso tempo para ministrar as aulas durante este projeto. Agradecimento especial a professora Nelza Mara Pallú, ao programa de Desenvolvimento Rural 
Sustentável - PPG-DRS, da Universidade Estadual do Oeste do Paraná - UNIOESTE, pela sua responsabilidade em nossa formação acadêmica, à Coordenação de Aperfeiçoamento de Pessoal de Nível Superior - CAPES e ao Conselho Nacional de Desenvolvimento Científico e Tecnológico - CNPq. Por fim, também agradecemos ao Grupo Interdisciplinar e Interinstitucional de Pesquisa e Extensão em Desenvolvimento Sustentável - GIIPEDES pelo abrigo e apoia à pesquisa.

\section{Referências}

Ahlert, A. (2001). Ensino e pesquisa: Uma dialética necessária. Caderno de educação física. Marechal Cândido Rondon. 3(2), 103-8.

Ahlert, A. (2021). Da migração ao conservadorismo: Ideologia e sustentabilidade ambiental no pensamento de confissão luterana no oeste do Paraná. Revista Unitas, 9(1). http://revista.fuv.edu.br/index.php/unitas/article/view/2509. http://dx.doi.org/10.35521/unitas.v9i1.2509.

Bardin, L. (1977). Análise de conteúdo. Ed 70.

Bortoloto, C. C. (2020). Políticas de imigração na Espanha e Brasil um estudo comparado das ações estatais frente aos grandes fluxos migratórios de 1980 a 2017. Revista Braz. J. of Develop., 6(12), 97642-61. https://www.brazilianjournals.com/index.php/BRJD /article/view/21530/17174.

Cavalcanti, L., De Oliveira, T. \& De Macedo, M. (2019). Resumo Executivo: Imigração e Refúgio no Brasil. A inserção do imigrante, solicitante de refúgio e refugiado no mercado de trabalho formal. OBMigra.

Dagnino, R. (2014). Tecnologia Social: contribuições conceituais e metodológicas. EDUEPB, 318 p.

De Mello, S. V. (Coord.). (2019). Perfil Socioeconômico dos Refugiados no Brasil: Subsídios para elaboração de políticas. Agência da UNO para refugiados (ACNUR). 71 p. https://www.acnur.org/portugues/wp-content/uploads/2019/07/Pesquisa-Perfil-Socioecon\%C3\%B4mico-Refugiados-ACNUR.pdf

Diniz, L. R. A. \& Neves, A. de O. (2018). Políticas Linguísticas de (In)Visibilização de estudantes imigrantes e refugiados no ensino básico brasileiro. Revista $X, 13(1), 87-110$.

Exime, E. (2021). Cooperação internacional na perspectiva da agricultura familiar no Haiti. 163 f. Dissertação (Mestrado em Desenvolvimento Rural Sustentável) - Universidade Estadual do Oeste do Paraná, Marechal Cândido Rondon.

Fonseca, R. \& Serafim, M. (2010). A Tecnologia Social e seus arranjos institucionais. In: Dagnino, R. Tecnologia social: ferramenta para construir outra sociedade. (2a ed.), KOMEDI. 139-153.

Gil, A. C. (2009). Métodos e técnicas de pesquisa social. (6a ed.), Atlas.

Instituto Brasileiro de Geografia e Estatística - IBGE. (2010). Censo Brasileiro de 2010. IBGE.

Instituto Brasileiro de Geografia e Estatística - IBGE. (2021). Estimativa populacional 2021. https://cidades.ibge.gov.br/brasil/pr/marechal-candidorondon/panorama

Instituto Brasileiro de Geografia e Estatística - IBGE. (2020). Cai para 6,2 milhões números de trabalhadores afastados pela pandemia na $3^{\text {a }}$ semana de julho. Agência de notícias IBGE. https://agenciadenoticias.ibge.gov.br/agencia-sala-de-imprensa/2013-agencia-de-noticias/releases/28294-pesquisa-pulso-empresaentre-as-empresas-que-estavam-fechadas-na-1-quinzena-de-junho-39-4-encerraram-atividades-por-causa-da-pandemia

Instituto Brasileiro de Geografia e Estatística - IBGE. (2020). Pesquisa Nacional por Amostra de Domicílios Contínua - PNAD Contínua. IBGE. https://www.ibge.gov.br/estatisticas/sociais/trabalho/9173-pesquisa-nacional-por-amostra-de-domicilios-continua-trimestral.html?=\&t=serieshistoricas\&utm_source=landing\&utm_medium=explica\&utm_campaign=desemprego

Long, N. (2007). Sociología del Desarrollo: una perspectiva centrada en el actor. (H. Forjado, M. Villarreal \& P. Rodríguez, Trad.). Ciesa, 504 p

Long, N. \& Ploeg, J. D. (2011). Heterogeneidade, ator e estrutura: para a reconstituição do conceito de estrutura. In: Schneider, S. \& Gazolla, M. Os atores do desenvolvimento rural: perspectivas teóricas e práticas sociais. Editora da UFRGS, 21- 48 p.

Ludke, M. \& Andre, M. E. D. A. (2013). Pesquisas em educação: uma abordagem qualitativa. E.P.U.

Pike, A., Rodríguez-Pose, A. \& Tomaney, J. (2007). What Kind of Local and Regional Development and for Whom? Regional Studies, 41: 9, $1253-1269$.

Silva, L. F., Corrêa, I. C., Charão, A. S. \& Lima, J. V. F. (2017). ProgressCode: uma Ferramenta para Monitorar o Progresso de Alunos no Ensino Não-formal de Programação. In: Workshop sobre Educação em Computação (WEI), 25, São Paulo. Anais [...]. Porto Alegre: Sociedade Brasileira de Computação.

Silva, M. D da., \& Lima, L.V. (2021). Potencial de um sistema web para apoiar a aprendizagem na pandemia COVID-19 usando métodos eficazes para a construção do conhecimento. Research, Society and Development, 10 (11), e467101119824. https://doi.org/10.33448/rsd-v10i11.19824

Schmitt, C. J. (2011). Redes, atores e desenvolvimento rural: perspectivas na construção de uma abordagem relacional. Sociologias, 13(27), 82-112.

Simões, A., Cavalcanti, L. \& Pereda, L. (2019). Relatório Anual 2019: movimentação de trabalhadores imigrantes no mercado formal. OBMigra.

Vestena, R. de F., Beckmann, A. R. \& Peixoto, S. C. (2020). Integração universidade e escola na formação inicial em Pedagogia. Pesquisa, Sociedade e Desenvolvimento, 9(9). https://rsdjournal.org/index.php/rsd/article/view/7955 